\title{
Domination and Consumption: an Examination of Veganism, Anarchism, and Ecofeminism
}

\author{
IAN WERKHEISER
}

\section{Introduction}

Traditional academic work on non-human animals, ${ }^{1}$ which largely ignores the political and ethical aspects of humans' interactions with non-humans, has led in recent decades to the emergence of more radical scholarship addressing these issues directly, sometimes called Critical Animal Studies (CAS) (McCance). Some work which might be grouped into CAS can be found in radical environmental philosophy, particularly coming out of the ecofeminist tradition, which sees hierarchy and domination as fundamental to our broken relationship with non-human animals and the resultant abuse and mistreatment our society visits upon them (Adams, Sexual Politics; Kheel). However, these works often underplay the interlocking political and economic systems which support and benefit from those broken relationships, and often little is said about the revolutionary project of getting to a society with better relationships to the non-human world. At the same time, theories of anarchism have a deep critique of exploitation and unjustified authority, as well as well developed programs of revolutionary change. Anarchist critiques and vision have already proven to be valuable resources for a small but growing body of anarchisminformed CAS which avoids some of the gaps in the ecofeminist approach (Torres; Best; Nibert; Nocella). 
This is not to say, however, that anarchist thought is always sensitive to our domination of non-human animals. There is disagreement and debate among anarchists as to how non-human animals ought to be regarded. Though nearly all anarchists are against the unnecessary suffering of other animals, and have strong critiques of our exploitation of nature, they disagree about what our relationship with non-human animals ought to be. This comes into particular focus around the issue of the use and consumption of animal products. As we will see, some anarchists - such as the CAS authors noted above as well as activists in the Animal Liberation Front or ALF-advocate for veganism. Others - such as so-called "anarcho-primativists" activists and writers like Jensen ("Language") or Zerzan — support hunting and perhaps some forms of non-coercive semi-domestication. Still others - such as activists and scholars following the Social Ecology of Murray Bookchin—believe that how we relate to animals (human and otherwise) should be primarily dictated by the demands of a healthy ecosystem, rather than ethical obligations to an individual animal. Yet all three visions could be seen as informing conflicting visions of CAS. To help resolve these conflicts, I suggest that work in ecofeminist studies, in particular the work of Val Plumwood, might contribute to anarchist theory on ethical human-animal relations.

In this paper, I will first review some of the contributions anarchism can make to work on non-human animals. I will then explicate the different positions on veganism found within anarchist theory as a way into this intellectual tradition's positions on non-human animals, and argue that the ideas on which different kinds of anarchism agree can be a useful contribution to the discourse on humans' relationships with non-humans. I will also attempt to resolve some of the tensions within anarchism in regards to veganism, and show that the work of Val Plumwood can offer an at least prima facie plausible solution to the debate. However, I will show that while 
Plumwood's position can resolve many of the questions of domination and exploitation which are so central to anarchist thought, there is an important remainder of compassion, which cannot be so easily addressed. Ultimately I will show that anarchism and some of the more radical strains of environmental philosophy such as ecofeminism can greatly contribute to each other and to Critical Animal Studies.

\section{Anarchism and Animals}

Due to the underrepresentation and misrepresentation of "anarchism" in mainstream conversation and academic discourse, it is perhaps necessary to briefly address what is meant by the term. As Cochrane writes:

The word 'anarchy' has been subjected to a gross (and arguably ideological) distortion in its meaning. Equated in everyday usage with chaos, disorder, and unprovoked violence, and even terrorism, an ecopolitics described as anarchist is thus unfortunately likely to inspire fear and revulsion in those unfamiliar with this political orientation. Moreover, others who possess only a limited understanding of the term - and this is especially true of many social democrats and state-centered socialists-tend to dismiss the anarchist rejection of the state as naïve and simplistic, insisting instead that the state is essential for the ordering of complex modern societies. ("Bioregion" 3)

To these two ideas of anarchism as chaos or naïveté we might add the idea of "libertarianism", which in the U.S. is synonymous with an opposition to the state, either entirely or at anything above a minimal level, but coupled with an acceptance of capitalist economic relations. Anarchists coming out of the traditional left-wing orientation of anarchism see libertarianism as being an incompatible ideology. Anarchism is opposed to domination and exploitation in all forms, not merely as embodied in the state, and so it rejects libertarianism's endorsement of the "unaccountable private tyrannies" (Chomsky) of corporations. These three versions of "anarchism" are common in mainstream and academic discourse (Nozick). 
Of course, anarchism is a term that covers widely diverse beliefs and, as we will see in this paper, anarchists often disagree with each other over quite important topics. Nevertheless, there are some shared key characteristics, and these look very different from the popular conception of the term. A helpful definition of anarchism was provided by the highly influential anarchist thinker Peter Kropotkin. Anarchism, he writes, is

The name given to a principle or theory of life and conduct under which society is conceived without government-harmony in such a society being obtained, not by submission to law, or by obedience to any authority, but by free agreements concluded between the various groups, territorial and professional, freely constituted for the sake of production and consumption, as also for the satisfaction of the infinite variety of needs and aspirations of a civilized being. (Kropotkin, "Anarchism" 914)

This idea of "free agreements" is based on Kropotkin's idea of "mutual aid", the idea that in nature virtually all species engage in cooperation (rather than "the war of all against all" common in the kind of popularized Darwinism against which Kropotkin was responding) for survival, both within and between species (Kropotkin, "Mutual Aid"). For over a hundred years, then, anarchists have been developing an analysis of the problems of unjustified hierarchy, exploitation, and domination, and insisting that the state is not a solution to these problems but rather a servant of the abuses of capitalism as well as itself inherently a locus of domination and illegitimate hierarchy. Anarchists moreover indicate the social, cultural, interpersonal, and internal radical changes that are necessary to redress these wrongs and, without imposing inflexible rules on the future, they provide descriptions of what an an-archic, non-coercive, nonexploitative society might look like (Proudhon; Goldman; Jensen, “Endgame”).

Though anarchism is underrepresented in mainstream academic discourse (Graeber), there have been a few attempts to bring its insights to bear on questions in environmental philosophy and bioethics (Cochrane; Torres), and its presence in CAS is growing. The attempt 
most relevant to this paper is "Beyond the human: extending ecological anarchism" by Matthew Hall. In this essay, Hall argues that the theoretical critique of coercive authority and illegitimate hierarchy in anarchism "Represents a promising basis for a more environmental culture" (374). Yet, as Hall points out, anarchism's usefulness as a resource for environmental philosophy does not mean that all anarchism has an adequate or useful conception of the natural world. There has been some in-depth work in anarchist theory on the environment (Reclus; Bookchin; Zerzan; Jensen, "Language"), however this is not universal across all branches of anarchist thought. For example, some strains of anarchism, though opposed to intra-human oppression in all its forms, recapitulates the human separation from and superiority to the rest of nature, and thereby justifies any exploitation of the world which benefits humans (Hall 378). As a result, Hall calls for the merging of the analysis of power in anarchism and its explicitly political program with the analysis from radical environmental philosophy (particularly coming out of ecofeminist philosophy) of the divide between humans and non-humans in our culture and its basic grounding of our abuse of the non-human Other (386-8). One author whose work Hall suggests is particularly useful in this merging of anarchist and radical environmental thought is ecofeminist philosopher Val Plumwood, whose reflections on vegetarianism I will be engaging with below. This paper can thus be seen as an attempt to put Hall's suggestion into practice in the particular case of veganism.

A good example of the potential contribution of anarchism to mainstream political theory, of the divisions between different versions of anarchism, and of the usefulness of radical environmental philosophy in helping us out of these divisions within anarchist thought, can be found in the anarchist debates over consuming non-human animals and their products. The consumption of non-human animals is a highly contentious issue, and questions within anarchist 
theory_-for instance: Is eating animals another form of exploitation or domination of nature, or is it, on the contrary, an expression of our continuity with nature? Can the eating of animals be done both justifiably and unjustifiably depending on context, and, if so, what are the requirements? - put simple claims against hierarchical, subject-object distinctions between human nature to the test, and force us to deepen our analysis. In the next sections we will look at the positions different versions of anarchism have taken with respect to the consumption of nonhumans and their products, and use the work of Plumwood to move towards the resolution of these disagreements.

\section{Veganarchism}

In 1995, the anarchist activist and writer Brian Dominick published an influential pamphlet entitled "Animal Liberation and Social Revolution", which promoted a necessary connection between anarchism and veganism, into a movement he called "Veganarchism". As he writes in the pamphlet:

I am vegan because I have compassion for animals; I see them as beings possessed of value not unlike humans. I am an anarchist because I have that same compassion for humans, and because I refuse to settle for compromised perspectives, half-assed strategies and sold-out objectives. As a radical, my approach to animal and human liberation is without compromise: total freedom for all, or else. ... Any approach to social change must be comprised of an understanding not only of social relationships, but also of the relationships between humans and nature, including non-human animals. ... No approach to animal liberation is feasible without a thorough understanding of and immersion in the social revolutionary endeavor. (5)

It should be pointed out that here Dominick is continuing a tradition within anarchism beginning with (at least) the anarchist writer and philosopher Élisée Reclus, who at the beginning of the twentieth century wrote a strikingly modern biocentric defense of vegetarianism, arguing that our treatment of non-human animals is intimately connected to wars of colonization and our general 
domination of nature, and that these phenomena must be addressed as manifestations of the single problem of our desire to dominate and exploit (Reclus).

Dominick and other veganarchists (Zezima) agree with those feminist, critical race, and class analyses (Adams, Sexual Politics; Spiegel; Torres) that connect the exploitation of nonhumans with the oppression of marginalized groups of humans. Dominick writes that intrahuman oppression such as racism, sexism, classism, and ageism are based on the same roots as oppression of non-humans, and must be addressed as a whole: "To decide one oppression is valid and the other not is to consciously limit one's understanding of the world; it is to engage oneself in voluntary ignorance, more often than not for personal convenience" (10).

Dominick argues that veganism is not merely a consumer choice, even an ethically motivated one, enacted within a capitalist system. Indeed, he is very critical of liberal conceptions of veganism which worry about the suffering of non-human animals but do not see it as a problem of domination and exploitation that is inextricable from the larger problems of capitalism. As Dominick writes,

Pure vegetarianism is not veganism. Refusing to consume the products of non-human animals, while a wonderful life choice, is not in itself veganism. The vegan bases her choices on a radical understanding of what animal oppression really is, and her lifestyle choice is highly informed and politicized. ... Many vegetarians fail to see the validity of human liberation causes, or see them as subordinate in importance to those of animals who cannot stand up for themselves. (8)

So while veganism is in part a change of consumption patterns, for anarchists there is no illusion that consumption alone will make the requisite changes, nor even that one is not hurting animals (human and non-human) when consuming anything within the industrial capitalist social and economic system of domination and exploitation. Rather, veganism is a natural outcome of a resistance to domination and exploitation. As Torres argues, "As a needless and unnecessary 
form of hierarchy, anarchists should reject the consumption, enslavement, and subjugation of non-human animals for human ends, and identify it as yet another oppressive aspect of the relations of capital and a needless form of domination" (209). This is a radical position, but one that does occur in the more radical wing of mainstream thought on non-human animals, in particular ecofeminism. Ecofeminism has been defined as supporting the idea that "There are important connections - historical, experiential, symbolic, theoretical-between the domination of women and the domination of nature" (Warren 126). As part of these connections, many ecofeminists argue that "speciesism"-an intentional parallel of sexism-is the root of our exploitation of non-humans (Collard and Contrucci; Adams, Sexual Politics; Kheel).

The difference between anarchist veganism or veganarchism and other radical vegan discourses is the perception of, as Dominick says, "The need for total revolution" (9), veganarchism also has a model of how that revolution could be pursued, and some indication of what non-exploitative, non-hierarchical relationships might look like. These understandings are where anarchism can be most helpful for work on connecting diet to a richer political practice. For example, veganarchists critique the idea of working for welfare laws to protect non-human animals as a means to get us to a non-dominating relationship. The state and its laws, as Dominick points out, are on the side of those with power and decidedly anti-animal (11). Anarchists argue generally (Bakunin; Goldman; Berkman) that the state and its laws are inherently unjust because they are founded on forced coercion, and always recapitulate current unjust power relations because they are captured by the interests of the already-powerful. Thus while some reforms may be allowed to go through, ultimately the fundamental power relationships cannot be changed from within the political system. 
The same critique is also applied to working within the economic system. Anarchists believe that mere consumption within capitalism will likewise fail to bring about the change needed. As Dominick writes, "Such thinking exposes the liberal vegetarian's ignorance not only of human oppression, but of the deep-seated connectedness between the capitalist system at large and the industries of animal oppression" (Dominick 8). Even more than petitioning the state, petitioning capitalism via consumptive choices will not lead to a dismantling of the fundamentally unjust power relationships in the economy. Indeed, many anarchists have criticized the tendency of modern institutions and even social movements to get us to define ourselves and our possible actions in terms of consumption, and see this as a continuation of the diminution of our freedom that our social, political, cultural, and economic systems have long pursued. As Derrick Jensen has argued, our redefinition from "citizen" to "consumer" "Is as wrenching, alienating, demeaning, disempowering, and wrong as this culture's previous redefinition of us from human animals in functioning communities to citizens of nation-states. Each of these redefinitions gravely reduces our range of possible forms of resistance" (Jensen, What We Leave 259). Anarchists, then, believe that opposition to the entire interlocking system of power is essential to making fundamental change, and veganarchists include within that ambit our relationship with non-human animals.

One might wonder, however, if systematic change is the only thing that can be effective, why veganarchists would also call for eliminating the consumption of non-human animal products from our own individual lives at all. We might well ask whether it would not be more effective to devote our time and energy toward systematic change and not worry about the ultimately irrelevant personal choices we make. Here it is important to understand the anarchist concept of the "propaganda of the deed." This term has sometimes been used to refer only or 
primarily to violent deeds which show that the powerful can be resisted effectively (Most). However its common meaning in modern times has been as a form of prefigurative politics (Breines; Graeber), the idea that anarchists must not only advocate for different relationships based on cooperation and mutual aid, nor only fight to achieve them, but must also show that such relationships are possible and begin to create them. As the anarchist writer Gustav Landauer wrote, "The state is a relationship between human beings. ... One destroys it by entering into other relationships" (Landauer, "Destroying” 123). Thus veganarchists believe that they ought to not only fight to change our current domination of non-human animals, but should also simultaneously begin to build an alternative society characterized by different relations with nonhuman animals.

\section{Compassion and Alienation}

One final point in the veganarchist argument must be addressed, because as we will see below, though it too comes out of traditional anarchist theory, it is the least compatible with nonvegan anarchism. An important concept in anarchism (as well as in the works of Hegel and Marx) is alienation. For anarchists, alienation usually means the inability of people to see their exploitation and their consequential belief that the domination of their lives by the state and corporations is justified (Zerzan). For veganarchists, this alienation includes an ignorance of the realities of our exploitation of non-human animals. This entails keeping much of the work of "meat" production ${ }^{2}$ away from the public, for example by making it illegal to film animal cruelty in factory farms and slaughterhouses (Carlson). However, for veganarchists, even hunters in our society are alienated from animal suffering ${ }^{3}$. This is because our culture reinforces the idea that humans are uniquely superior to other animals, that we are natural predators and carnivores, and 
that non-human animals do not particularly suffer as they are raised in captivity for the purpose of being slaughtered (AbdelRahim).

The idea that this alienation is a large part of why we consent to this system is based on an argument from natural compassion. Veganarchists are committed to the idea that humans have a natural compassion toward the suffering of others, and that other orientations such as callousness or taking pleasure in others' pain are unnatural and require effort to create and maintain. As Dominick says in his chapter on alienation, "The vegan understands that human exploitation and consumption of animals is facilitated by alienation. People would not be able to live the way they do - at the expense and suffering of animals — were they to understand the real effects of such consumption" (14). This argument is based in part on children's reactions to the suffering of all animals, and an implicit argument in phenomenology: there is an appeal that you, the reader, do in fact have intersubjective compassion for the suffering and death of others, both human and non-human.

\section{Disagreements}

Not all anarchists are vegan. In this section I will look at some of the prominent critiques of veganism within the anarchist tradition and in anti-hierarchical philosophy. I will largely ignore those critiques which arise from the branches of anarchism that do not see non-human animal suffering as significant, which means avoiding (for example) Social Ecology, an important strain in anarchism started by Murray Bookchin. Social Ecology worries about the environment and humans living sustainably within it, but sees a concern for the suffering of nonhuman animals as "Cheapen[ing] the meaning of real [human] suffering and cruelty" (Bookchin 362). Instead, I will concentrate on those strains of anarchism that take seriously non-human 
animals and see their suffering, and our domination of them, as important issues, but which do not believe that veganarchism is the right way to have a better relationship with other animals. One prominent type of criticism is that veganarchism is, inescapably, the very things it denies being: consumerist, reformist, welfarist, and so on. Essentially these claims are that the veganarchist arguments against these positions are insufficient, and perhaps necessarily so, because by pursuing veganism one reinforces the exploitative institutions in our society.

One example of this sort of internal critique (that veganarchism fails by its own standards) is found in the writings of Peter Gelderloos, who has directly criticized veganism in several papers ${ }^{4}$ ("Consumer Activity"; "Anarchist Perspective"). It is worth pointing out that Gelderloos's critiques are not unusual, and he is not anti-animal. As he says, for example, "Unlike veganism, animal liberation is, in my view, an important part of a full anarchist movement" ("Consumer Activity" 11). Nevertheless, "Fighting the exploitation of animals and veganism are not the same thing, and the question of whether the latter is useful for the former is also necessary to debate" ("Anarchist Perspective" 3-4). He has written that, at best, the term "vegan" brings together both people working for animal liberation and people working to save capitalism (for example those whose reason for veganism is that it will make our current system more sustainable), and so ought to be abandoned as a confusing ideology (3-4). At worst, Gelderloos argues, veganism will reinforce the systems of domination to which anarchists object, because it is inherently about consumption, and so contributes to the capitalist system, meaning that

All profit made from the buying and selling of this [vegan] food represents a return on investment, a cash flow that a diverse web of banks, insurance companies, and investors turn right around and put into other industries - the weapons industry, clothing manufacture, vivisection, adventure tourism, prosthetic devices, turkey factories, cobalt mining, student loans, it doesn't matter. ... Not only does veganism encourage an 
ignorance of market mechanisms, it also conflates consumption with agency and thus promotes a fundamental democratic myth. (Gelderloos, "Anarchist Perspective" 9-10)

Earlier we saw that considered veganarchism does not believe that purchasing and eating vegan food will bring about social change, and acknowledges that change at the level of systems must be pursued to actually help non-human animals. On this point vegan and non-vegan anarchists who care about non-human animals agree. The difference is whether maintaining vegan consumption while working toward this end is important. For veganarchists, recall that vegan consumption is seen as prefigurative politics via propaganda of the deed in the Landauerian sense. Gelderloos and similar anarchist writers disagree. For Gelderloos, anarchists who live a vegan lifestyle are not showing another possible world, because that vegan lifestyle would not be possible outside of the abundance and easy access of a wide variety of food provided by the industrial capitalist agricultural system. Anarchists who are actually using the propaganda of the deed by creating alternative economies outside of the dominant system, according to Gelderloos, quickly find that they have to abandon a vegan diet in order to have enough food to survive (Veganism: Why Not 11).

The internal critique, then, rests on two assumptions: (1) that a vegan lifestyle pursued today makes achieving a world free of domination more difficult because it shores up hierarchical and exploitative institutions, and (2) that a vegan society in the future which does not use an industrial, destructive food system is impossible. It seems that these questions are partly empirical and partly theoretical, but perhaps not impossible to answer. Presumably it would involve looking seriously at efforts being made toward intensive vegetable farming without industrial inputs (e.g. permaculture), and at societies which are largely vegetarian and/or vegan but do not have the privileged access to our industrial food system that the stereotypical 
white Western vegan does (e.g. communities in India and among Ital Rastafari). As far as I know, however, there have been few if any attempts to lay out a positive program as a response to these internal critiques.

Other than these internal critiques, there is another, more fundamental, form of criticism of veganism from within the anarchist tradition. This external critique rejects one of the key tenets in veganarchism: that it is wrong to kill or harm another sentient creature. For anarchists, the central wrong is domination and exploitation, and so if killing sentient creatures is always wrong, that must be because it is a form of domination. Indeed, veganarchists since Reclus (to anachronistically label him as such) have argued that killing is a profound form of domination. However, death is a natural part of the world and of life, and in nature often occurs at the hands of a predator. If one is committed to the idea, as anarchists are, that domination and exploitation are not inevitable parts of nature (unlike predation), then killing for food does not seem to be necessarily an act of domination. As Gelderloos writes, "The predator does not dominate the prey, nor does it negate them. It enters into a relationship with them, and this relationship is mutual - or in other words, of a sort that anarchists should find interesting and potentially inspiring” (“Anarchist Perspective” 5).

Moving away from non-human predation to the world of human societies, many anarchists (including many veganarchists) value contemporary and historical indigenous cultures which operate or operated anarchically as useful models. Some non-vegan anarchists, however, argue that few if any of these societies were vegan or saw being vegan as a desirable goal. Rather, non-vegan anarchists point to scholarship on indigenous societies (Whyte) which argue that these societies show there can be reciprocal but non-identical relationships between species that are anarchic and just, even if those just relationships involve killing. As Derrick Jensen 
suggests in a chapter where he advocates for eating meat while fighting to save non-human animals and their ecosystems, "When you take the life of someone to eat or otherwise use so you can survive, you become responsible for the survival—and dignity—of that other's community" (Endgame 138). This critique turns the argument from alienation back against veganarchists. Here vegans are the ones who are so alienated from nature that they are able to imagine that suffering and death are not necessary parts of a natural and whole life, and to imagine that it is possible to consume without causing suffering to non-human animals.

The external more than the internal critique, if true, poses a serious problem for any version of veganarchism, although not for all forms of veganism. Some forms of non-anarchist veganism may survive this critique because they argue on utilitarian, religious, or some other grounds that killing is always wrong regardless of its relationship to domination. The idea that anarchism and veganism necessarily imply each other is, however, cast into question by the external critique. To examine this question, I will next turn to the ecofeminist environmental philosophy of Val Plumwood, and show that her account can resolve this concern, although I will also argue that there is an unresolved remainder in Plumwood's work.

\section{Ontological and Contextual Veganism}

In her articles "Integrating Ethical Frameworks for Animals, Humans, and Nature: A Critical Feminist Eco-Social Analysis", and "Animals and Ecology: Towards a Better Integration", Plumwood describes most vegetarians as subscribing to what she calls "ontological

vegetarianism" which is the idea that "Nothing morally considerable should ever be ontologized as edible or as available for use" (Plumwood, "Integrating" 287). Plumwood argues that 
ontological veganism is inherently built on a profound and problematic separation between humans and non-humans.

This separation becomes clear, for Plumwood, when we consider the case of predation in nature. How are we to judge a wolf killing and eating a deer? If the ontological vegan says that the wolf is wrong to do so but doesn't know any better, then she is saying that humanity is special because humans have recognized a profound truth about nature of which no other animal is aware. Such a position also commits us to a strong moral realism and the claim that carnivores ought to become scavengers, which we might not want to hold. If the ontological vegan instead says that it is not wrong for the wolf to eat the deer, then she is saying that humanity has a special duty to others that no other species has, and depending on how this is cashed out, it will most likely come down to another kind of human exceptionalism. This might not be a problem if vegans are willing to bite the exceptionalism bullet, but given that most seem to be committed to ecological and biocentric arguments, it might be a bitter pill. Certainly for veganarchists, who advocate veganism as a critique of humanity's domination of non-humans, it is a serious problem and very akin to the external argument in the previous section.

Plumwood, however, describes another kind of vegetarianism, which she calls “contextual vegetarianism" (Plumwood, "Integrating" 289) ${ }^{6}$. This is the position that "It is not human predation itself we need to oppose, as in the ontological view, but what certain social frameworks have made of predation" (289). This allows us to justify vegetarianism in, for example, "Most urban contexts" (289), because of how non-human animals are treated in our society. Such a position can also continue to motivate a strong opposition to animal abuses and cruelty and a commitment to having a better relationship with them. That better relationship, in the end, however, will not be any kind of vegetarianism. Rather it will be what she calls 
"Ecological Animalism" (Plumwood, "Ecology" 1), a position that "Supports and celebrates animals and encourages a dialogical ethics of sharing and negotiation or partnership between humans and non-human animals, while undertaking a re-evaluation of human identity that affirms inclusion in animal and ecological spheres" (2). This negotiation or partnership will necessitate humans ethically eating non-human animals - and, for Plumwood, ethically being eaten by non-human animals (Plumwood, "Surviving")—in order to be ecologically compatible.

If this idea of contextual vegetarianism or veganism is combined with the anarchist points earlier about reciprocal, non-identical responsibilities that make killing a mutually positive rather than dominating relationship, then it might look as if we can resolve the differences between vegan and non-vegan anarchists. Non-vegans might be right that there can be homeworlds in which it is morally acceptable to eat non-human animals, but doing so is a terrible burden, and occasions a profound responsibility to that animal, its species, and its (and our) ecosystem. Those homeworlds are all ones in which we are not dominating those we eat, but rather live in complicated, non-identical, non-symmetrical, yet deeply reciprocal relationships of mutual aid. As we live in nothing like this kind of world now, then we currently have not earned the ability to eat non-human animals, and we ought to work toward that kind of world. Thus vegan and nonvegan anarchists could at least in theory come together as "contextual veganarchists".

If this position were accepted, and all anarchists were to become committed to contextual veganarchism, there still might be disagreement on whether or not to eat non-human animals today, while working toward that kind of a world. This disagreement would especially arise in situations where the alternative was at least arguably an even worse relationship. For example, when dealing with deer overpopulation, killing them and eating them might be a less disrespectful relationship than killing and not eating, or forcibly sterilizing, these animals. In 
such a situation, these imagined contextual veganarchists might think that the contextually most appropriate thing to do (assuming they didn't have the power to reintroduce wolves into the area to work as an ecological check) would be to eat the deer after killing them, while others would disagree. Even in the case of this sort of disagreement, however, contextualism gives the proper scope to this personal disagreement, and shows that contextual veganarchists who disagree on particular questions of context agree on social, economic, and political goals. Thus contextual veganarchists who dumpster dive to eat meat would be closer to the contextual veganarchist who never eats meat than is a capitalist, ontological vegetarian who is content to have the rainforest cut down to grow soybeans.

\section{The Remainder of Compassion}

Prima facie contextual veganarchism might seem to be a useful road toward reconciliation, since it takes seriously many of the concerns in both camps, and gives a contextualized answer to the question of whether killing is or is not a form of domination. However, it ignores the veganarchist argument from compassion, which is a kind of moral remainder, and may ultimately make the above resolution impossible.

For some, perhaps most, vegans, their aversion toward and desire to oppose non-human animal suffering did not follow out of ontological commitments. Rather the converse: from an early age, many vegans had an intersubjective, phenomenological compassion for the the suffering of non-human animals, and the intuition that this suffering was wrong, that was inexplicable within the ontology of their society, as is the case for many children (Pallotta; Hussar \& Harris). For this reason they rejected that dominant ontology, and either discovered or re-invented veganism. This is not the sort of compassion that can be altered by a more nuanced 
understanding of the question. Rather, the compassion toward non-humans, and the intuition that killing any animals to consume them is wrong is, for these vegans, a basic intuited truth which feeds up into more complex understandings of the world. The existence of this reaction may imply at least that committed vegans are unlikely to be brought around to eating meat in any sort of homeworld of different intersubjective relationships with non-humans. In other words, for at least some vegans, there is no relationship one could have with non-human animals that would justify eating them, any more than for at least some anarchists there is a homeworld in which we have a relationship to other humans that justifies our exploitation and domination of them.

This might be viewed as a mere idiosyncrasy on the part of these vegans, but recall the veganarchist argument that this compassion is the natural state for people to be in, from which they are alienated by society. It is difficult to resolve which reaction (compassion or noncompassion) is the more natural or less alienated to the suffering of non-humans, but research into empathy among very young children is at least suggestive (Hamlin et al.; Pallotta; Hussar \& Harris). One interesting example of the tension between an ecological outlook and intuitive compassion is found in Derrick Jensen's work. Jensen defends non-human animals because of his compassion toward them, yet he is not vegan. In his book, A Language Older Than Words, he speaks seriously about the silencing of animal suffering in our culture (as well as the suffering of human women, children, and other marginalized groups), and the imperative we all have to resist this silencing of alienation and listen. Listening to the suffering of others and taking it seriously might make killing and eating others a problem, and in the book he relates a friend's story about a flock of coots in a lake, which when approached by a bald eagle would wait for a time before one coot flew up and was eaten by the eagle (209). This story is presented as possibly being a case of non-human animals being willing to be eaten, and it seems to be an attempt to find a way 
out of the tension brought on by compassion (not a very likely one, unfortunately, given how often in nature non-human animals react very negatively to being preyed upon).

We are left, then, with a moral remainder in this attempt to solve the differences between vegan and non-vegan anarchists. Veganarchists may be committed to the idea that supporting a non-hierarchical ecology is a good thing, and acknowledge that this sort of ecology includes predation, yet nevertheless be unable to fully reconcile their compassion with the argument that they should therefore be willing in some contexts to kill and consume other animals.

\section{Conclusion}

As we have seen, anarchist thought has much to offer mainstream discourse. In the case of the question of the larger issue of our treatment of non-human animals, anarchism offers a systematic understanding of the underpinnings of our culture's domination of non-humans, and offers a program of resistance. Among anarchists who take non-human animals seriously, whether vegan or non-vegan, there are broad agreements that our domination of other animals is intimately interwoven in our social, cultural, economic, and political systems, and anarchism suggests strategies such as solidarity, propaganda of the deed, radical resistance, and others (which I have only briefly touched on in this paper), which might allow us to change even such deeply institutionalized injustices. Anarchism, then, has much to offer Critical Animal Studies, and greater links between anarchist animal activists and CAS scholars seems warranted.

We have also seen that some of the work in radical environmental philosophy, such as the ecofeminist writings of Val Plumwood, can deepen the conversation in anarchist discourse, and may help to resolve some of the apparent problems between vegan and non-vegan anarchists. This is all to the good, and suggests further combinations and collaborations between the two 
discourses. However, in the case of consuming what is produced from the suffering of nonhuman animals, the unavoidable phenomenal compassion may be a stumbling block to this hybrid system. Regardless, it is clear that anarchist animal activists, and anarchism-informed and ecofeminism-informed CAS scholars, can greatly benefit from increased dialogue.

\section{Notes}

${ }^{1}$ In this paper I will follow many scholars in using the phrase "non-human animals" to highlight the fact that humans are animals as well, rather than some entirely different thing set apart from the animal world.

2 As some authors, such as Carol Adams (Sexual Politics) have pointed out, part of the "production" is the creation of the term "meat" in the first place, which Adams argues is a "false mass term" alienating us from the corpse of an animal that suffered and died.

${ }^{3}$ Most ecofeminists, too, see hunters as alienated from suffering. See, for instance, Collard and Contrucci, Adams (Neither Man nor Beast) and Kheel. This is in contrast to some feminist work outside the ecofeminist tradition, such as Strange's Woman the Hunter, which sees hunting as a way of disrupting patriarchy and celebrating women's power.

${ }^{4}$ In this paper I am engaging with Gelderloos's strongest arguments, and ignoring others I find weaker, such as arguing that vegetarianism is inherently unhealthy.

${ }^{5}$ Plumwood refers to vegetarianism rather than veganism, but uses it in the way we have been using veganism in this paper.

${ }^{6}$ Plumwood did not invent the term "contextual vegetarianism," nor pioneer using it in an ecofeminist context. Deane Curtin uses the phrase in an argument for care ethics being brought to bear on our relationships to non-human animals. However, Plumwood's formulation, in particular the goal of "Ecological Animalism", is the most useful for our present purposes. 


\section{Works Cited}

AbdelRahim, Layla. Order and the Literary Rendering of Chaos: Children's Literature as Knowledge, Culture, and Social Foundation (Doctoral dissertation). Retrieved from ProQuest Dissertations and Theses (Access Order No. NR77978), 2011.

Adams, Carol J. The Sexual Politics of Meat: A Feminist-Vegetarian Critical Theory. New York: Continuum, 1990.

—. Neither Man nor Beast: Feminism and the Defense of Animals. New York: Continuum Press, 1994.

Bakunin, Mikhail. God and the State. Reprinted (1970) New York: Dover Publications, 1871.

Berkman, Alexander. Now and After: The ABC of Communist Anarchism. New York: Vanguard Press, 1929.

Best, Steven. "Rethinking Revolution: Total Liberation, Alliance Politics, and a Prolegomena to Resistance Movements in the Twenty-First Century," in Contemporary Anarchist Studies: an Introduction Anthology of Anarchy in the Academy. New York: Routledge, 2009: 189-200.

Bookchin, Murray. The Ecology of Freedom: The Emergence and Dissolution of Society. Palo Alto: Cheshire Books, 1982.

Breines, Wini. Community and Organization in the New Left, 1962-1968: The Great Refusal. New Brunswick: Rutgers University Press, 1989.

Carlson, Cody. "The Ag Gag Laws: Hiding Factory Farm Abuses From Public Scrutiny," in The Atlantic, TheAtlantic.com, 2012.

Chomsky, Noam. "State and corp," in Znet Communications ZnetCommunications.org, 2005.

Cochrane, Regina. "Bioregion, eco-polis, and eco (nomic)-federation: left-libertarian models of sustainability," in Encyclopedia of Life Support Systems, EOLSS.net, Oxford: EOLSS Publishers, 2002.

Collard, Andree \& Joyce Contrucci. Rape of the Wild: Man's Violence Against Animals and the Earth Bloomington: Indiana University Press, 1989.

Curtin, Deane. "Toward an Ecological Ethic of Care," in Hypatia 6, no. 1 (1991): 60-74.

Dominick, Brian A. Animal Liberation and Social Revolution: A Vegan Perspective on Anarchism or an Anarchist Perspective on Veganism. Syracuse: Critical Mess Media, 1995.

Gelderloos, Peter. "Veganism is a Consumer Activity." Infoshop News news.infoshop.org, 2008.

—. "Veganism: Why Not - An Anarchist Perspective." Infoshop News news.infoshop.org, 2011. 
Goldman, Emma. Anarchism and Other Essays. Reprinted (1969) New York: Dover Publications, 1910.

Graeber, David. Fragments of an Anarchist Anthropology. Chicago: Prickly Paradigm Press, 2004.

Hall, Matthew. "Beyond the human: extending ecological anarchism," in Environmental Politics 20, no. 3 (2011): 374-90.

Hamlin, J Kiley. Karen Wynn \& Paul Bloom. “Social Evaluation by Preverbal Infants," in Nature 450:22 (2007): 557-60.

Hussar, K. M. \& P. L. Harris. "Children Who Chose Not to Eat Meat: A Study of Early Moral DecisionMaking," in Social Development. 19, no. 3 (2001): 627-641.

Jensen, Derrick. A Language Older Than Words. White River Junction: Chelsea Green Publishing, 2004.

—. Endgame, Vol. 1: The Problem of Civilization. New York: Seven Stories Press, 2006.

—. What We Leave Behind. New York: Seven Stories Press, 2009.

Kheel, Marti. Nature Ethics: An Ecofeminist Perspective. Lanham: Rowman \& Littlefield Publishers, 2007.

Kropotkin, Peter. "Anarchism," in Encyclopedia Britannica Eleventh Edition, Vol. 1 Cambridge: Cambridge University Press, 1910.

—. Mutual Aid: A Factor of Evolution. Reprinted (2008) Hong Kong: Forgotten Books, 1902.

Landauer, Gustav. "Destroying the State by Creating Socialism" Anarchism: A Documentary History of Libertarian Ideas, Volume 1 Robert Graham (ed.) Montreal: Black Rose Books, 1910.

McCance, Dawne. Critical Animal Studies: An Introduction. New York: State University of New York Press, 2013.

Most, Johann. “Action as Propaganda” Reprinted (2003) The Anarchy Archives, Pitzer.edu, 1855.

Nibert, David. "Origins and Consequences of the Animal Industrial Complex" The Global Industrial Complex: Systems of Domination. New York: Lexington Books, 2011: 197-210.

Nocella, Anthony J. "Animal Advocates for Prison and Slave Abolition: A Transformative Justice Approach to Movement Politics for an End to Racism" Journal for Critical Animal Studies. 10, no. 2 (2012): 119-26.

Nozick, Robert. Anarchy, State, and Utopia New York: Basic Books, 1977. 
Palotta, N. R. "Origin of Adult Animal Rights Lifestyle in Childhood Responsiveness to Animal Suffering," in Society \& Animals. 16, no. 2 (2008): 149-170.

Plumwood, Val. "Integrating Ethical Frameworks for Animals, Humans, and Nature: A Critical Feminist Eco-Socialist Analysis," in Ethics and the Environment 5, no. 2 (2000): 285-322.

-. "Surviving a Crocodile Attack," in The Ultimate Journey: Inspiring Stories of Living and Dying Palo Alto: Travelers' Tales, 2000.

—. Environmental Culture: The Ecological Crisis of Reason. New York: Routledge, 2002.

—. "Animals and Ecology: Towards a Better Integration" (Working paper). Retrieved from Australian National University Digital Collections, 2003.

Proudhon, Pierre-Joseph (1840) What is Property?: or, An Iniquiry into the Principle of Right and Government. Reprinted (2010) New York: FQ Publishing.

Reclus, Élisée. “On Vegetarianism” The Humane Review Reprinted (2009) The Anarchist Library TheAnarchistLibrary.org, 1901.

Spiegel, Marjorie. The Dreaded Comparison: Human and Animal Slavery ( ${ }^{\text {rd }}$ Edition). New York: Mirror Books, 1997.

Strange, Mary Zeiss. Woman the Hunter. Boston: Beacon Press, 1997.

Torres, Bob. Making a Killing: The Political Economy of Animal Rights. Oakland: AK Press, 2007.

Warren, Karen. "The Promise and Power of Ecofeminism," in Environmental Ethics 12, no. 2 (1990). 125-146.

Whyte, Kyle. “Justice Forward: Tribes, Climate Adaptation and Responsibility," Climatic Change DOI 10.1007/s10584-013-0743-2 (2013).

Zerzan, John. Running on Emptiness. Port Townsend: Feral House Publishing, 2002.

Zezima, Michael. "More militant vegans, less ethical butchers" Dissident Voice Dissidentvoice.org (2009). 